\title{
Residências Terapêuticas e a cidade: enfrentamentos de normas sociais vigentes
}

Therapeutic Residences and the city: confrontations of existing social norms

José Alberto Roza Junior ${ }^{\mathbf{1}}$, Ana Maria Loffredo $\mathbf{2}$

RESUMO O presente artigo propõe um diálogo sobre Residências Terapêuticas e apropriação da cidade a partir do tema da desinstitucionalização de ex-moradores de hospitais psiquiátricos e seu retorno à cidade. $\mathrm{O}$ artigo estabelece problematização sobre reparação de danos, além da ruptura da condição de vida desses moradores, o que só parece ser possível quando a loucura ultrapassa a questão da diferença e adentra o âmbito da segregação social, extrapolando em muito o saber psiquiátrico e colocando a existência do louco no interior da realidade compartilhada por todos os fragilizados e segregados das possibilidades de troca social.

PALAVRAS-CHAVE Transtornos mentais. Segregação social. Desinstitucionalização. Reparação de danos.

ABSTRACT The present article proposes a dialogue about Therapeutic Residences and appropriation of the city from the theme of deinstitutionalization of former residents of psychiatric hospitals and their return to the city. The article establishes the problematization on damage reparation, as well as the rupture of the living conditions of these residents, which only seems to be possible when the madness goes beyond the difference's matter and enters the scope of social segregation, extrapolating in much the psychiatric knowledge and placing the existence of the madman within the reality shared by all the fragile and segregated of the possibilities of social exchange.

KEYWORDS Mental disorders. Social segregation. Deinstitutionalization. Compensation and redress. 


\section{Introdução}

A história dos hospitais psiquiátricos se anuncia para além da construção de edifícios que confinaram os loucos durante anos: os 'manicômios', que fazem parte da cultura que segrega pessoas impossibilitando-as de habitar a cidade. Cenas manicomiais expostas ao longo dos anos de Movimento Antimanicomial fornecem

condições necessárias para libertar-se da aceitação cotidiana da guerra e para provocar um horror e uma indignação mais generalizados, que apoiem e estimulem o clamor por justiça e pelo fim da violência1(26).

A busca da liberdade para habitar a cidade torna-se ponto nodal na discussão deste artigo, tendo a problematização das normas sociais vigentes como mote para se pensar a garantia de direitos às pessoas que tiveram seus corpos presos por anos nesses hospitais, ainda que a saída dessas instituições não necessariamente garanta a liberdade de se viver na cidade novamente.

Sabe-se da possibilidade de que o clamor de justiça se faça na ideia de construção de hospitais limpos, organizados, embora a lógica hospitalocêntrica se mantenha. Assim, quando se expõe a necessidade do louco de ser reconhecido como cidadão, alterando, inclusive, o seu lugar de moradia, tem-se um impasse importante na sociedade. A 'fotografia' ganha vida, habita a cidade e incomoda por seus questionamentos.

No livro 'Holocausto brasileiro'2, da jornalista Daniela Arbex, grande parte das pessoas pode se solidarizar com a situação desses moradores e, inclusive, questionar as violências praticadas na 'Era dos Manicômios'. Assim, não restaria dúvidas quanto às violências retratadas nesse livro e em fotografias, músicas, contos, documentários - a arte tem feito esse trabalho no decurso de muitos anos - que aludem ao não cuidado presente nessas instituições. Porém, como proceder quando esses mesmos loucos deixam o lugar da 'fotografia' e tornam-se vizinhos, habitantes da mesma cidade?

A hipótese é de que poucos habitantes da cidade acreditam na eficácia dos 'tratamentos' realizados com esses loucos nos manicômios. Não obstante, quando retornam para a cidade, muitos deles se questionam sobre o porquê de não poderem morar num lugar afastado, com a brisa do campo, grandes 'jardins', ou seja, o hospital psiquiátrico. Conforme dito anteriormente, eles parecem não querer um hospital sujo como viram nos documentários, mas um hospital limpo, com comida de qualidade, colchões para dormir, cadeiras para se sentar, equipe disponível 24 horas por dia, pronta para o 'cuidado'. Para uma grande parcela da população, a não violência seria um hospital isolado, mas de qualidade. Poucos reconhecem que a existência do hospital psiquiátrico - um lugar de onde o louco jamais poderia sair - já é violenta por si. E quando esse indivíduo anda na rua, sozinho ou acompanhado, os vizinhos - sob o estigma da tutela - podem verbalizar que ele, o que 'fala sozinho' e veste-se da maneira que escolhe, não está recebendo o cuidado devido.

Assim, as políticas públicas precisam ser compreendidas em suas preconizações, mas, acima de tudo, é preciso examinar como a sua prática se estabelece. É possível formular que a construção física de muros - que separam as pessoas que podem habitar a cidade e as que estão confinadas ao manicômio - contribui para a estruturação das marcas sociais que definem a vinculação com a sociedade, interditada para aqueles pacientes-moradores e determinada pela ideia de periculosidade a eles atribuída.

As ações revolucionárias, como no caso da Reforma Psiquiátrica, precisam se relacionar com as ações e o engajamento dos atores envolvidos num processo de mudança das classes sociais, especialmente na maneira de nos situarmos no mundo e de coexistir. Para tanto, a liberdade e a motivação se tornam indispensáveis para uma nova concepção, 
que apague a distinção entre intelectual e operário, entre 'normal' e 'louco'3.

Nesse sentido, tem-se a necessidade dos Serviços Residenciais Terapêuticos (SRT) - mais conhecidos como Residências Terapêuticas (RT) -, definidos por meio da Portaria GM n ${ }^{0}$ 106/2000 como

moradias ou casas inseridas, preferencialmente, na comunidade, destinadas a cuidar dos portadores de transtornos mentais egressos de internações psiquiátricas de longa permanência, os quais não possuam suporte social e laços familiares ${ }^{\mathbf{4 ( 2 3 )}}$.

Por conseguinte, a Lei $\mathrm{n}^{0} 10.216 / 015$, com suas estratégias propostas para os usuários do serviço de saúde mental, veio reforçar a importância das RT para o processo de desinstitucionalização. Todavia, é fundamental compreender que, embora a referida portaria seja essencial, essa discussão precisa acontecer para além da implantação dessa política pública em saúde. Este artigo convoca o leitor para a discussão sobre as normas para habitar uma cidade.

Desse modo, a função das RT ultrapassa uma resposta à cronificação e à segregação social, apresentando-se como um dos dispositivos de cuidado que aborda uma das modalidades mais difíceis da Reforma Psiquiátrica, no que diz respeito às dificuldades contemporâneas do habitar, uma vez que essas são casas para moradores antes segregados nos hospitais psiquiátricos. A sociedade, por sua vez, precisa ser compreendida como sustentação desses longos anos de internação hospitalar dos atuais moradores de RT.

Nesses termos, não se pode correr o risco de estabelecer uma tutela parecida com a exercida no interior do hospital, mas deve-se entender que é preciso agir na contracorrente dessa tutela, no cotidiano de trabalho. Legitimar o morador como proprietário da casa, incluindo seus direitos, mas, também, seus deveres para com os demais moradores, é essencial para esse início do processo de morar. Legitimar suas relações com os vizinhos, o comércio local e a cidade caracteriza-se pela compreensão da existência de cidadãos e não somente egressos de longas internações psiquiátricas:

A questão do relacionamento com o outro é uma constante em toda a temática do cuidado de si. Foucault sublinha em numerosas ocasiões a necessidade deste vínculo intersubjetivo (em forma agonística). Sem a presença do outro não se pode produzir nenhum relacionamento satisfatório; o cuidado de si precisa do outro. A constituição do indivíduo como sujeito ético efetua-se só por meio de relações complexas com o outro (cujo estatuto e formas são diferentes segundo a época). O outro é indispensável na cultura de si6(126).

A mudança para a RT - enquanto um dispositivo da rede de atenção psicossocial - estabelece a possibilidade desses moradores com a cidade. Para isso, é preciso suportar toda a complexa teia que se estabelece a seguir: os vizinhos, os transeuntes questionando: ‘que casa é essa?'. Não há como negar que essa casa é diferente.

Não se trata de reduzir essa moradia a qualquer outra casa da rua, mas de estabelecer que essa casa diferente não se constitui simplesmente pelo fato de nela habitarem moradores egressos de hospitais psiquiátricos, mas, antes, pelo fato de que esses moradores poderão questionar, a todo instante, a lógica imperante da cidade, obscurecida pela rotina do cotidiano dos demais moradores. O critério se estabelece nesse ponto, pois não necessariamente uma RT é por si um dispositivo questionador. Muito disso se dá na compreensão dos profissionais de saúde mental que estejam realmente afinados com as discussões acerca da loucura e da luta antimanicomial.

Nesse sentido, o outro será tanto o antigo vizinho quanto o novo morador da rua, loucos, alienados ou potencialmente questionadores da norma social vigente: o papel 
do outro é indispensável para a produção de um esboço de si compreensível.

Tal pensamento constitui uma constante de toda a tradição greco-romana. Portanto, Foucault não reivindica em suas análises uma autoconstituição isolada que exclua qualquer relacionamento com o outro, mas, para ele, o outro está sempre presente na origem da constituição estética de si, na figura do mestre, guia, professor, diretor de consciência e amigo ${ }^{6}$.

O árduo trabalho será o de construir, na comunidade, um lugar para os novos moradores. Como promover uma ética de existência em um sujeito que não é reconhecido pelo outro? A partir da exclusão histórica estabelecida e do retorno do louco para a sociedade contemporânea, como garantir que essas pessoas cuidem de si nas várias esferas da vida, tanto no cuidado com o dinheiro, mas, também, nas questões pertinentes ao amor, ao prazer, aos relacionamentos? Portanto, importa destacar que, para além do liberalismo, podemos lançar mão do pluralismo:

A ética e a sociabilidade tem sua origem na desdobra da relação primária do face-a-face. Para Levinas, a comunidade deve constituir-se sobre a base das relações intersubjetivas, mediante a responsabilidade pelo outro e a substituição. Ao liberalismo opõe-se o pluralismo. O primeiro só apreende o outro como um segundo exemplar do eu, enquanto o pluralismo permite perceber o outro em sua alteridade. Sob o fundamento da proximidade do outro será possível o surgimento da comunidade 6(142).

O conceito de comunidade pode ser construído para além do que se parece ter atualmente, na lógica das cidades, estabelecido por seus habitantes. Desprovido do romantismo ingênuo que levaria a pensar que essas pessoas deveriam ser de pronto incorporadas na vizinhança e na cidade, destaca-se que o papel da RT se efetiva no dia a dia da comunidade na qual está instalada, funcionando tanto para 'dentro do portão', estabelecendo-se nas relações entre os moradores e a equipe de apoio, quanto para 'fora do portão', com os vizinhos e serviços disponíveis na comunidade em questão.

Ao refletir sobre a loucura, insiste-se que os muros sociais, esses mais difíceis de lidar, precisam ser trabalhados no cotidiano. Há algo sobre a imaginação ocidental com relação ao lugar da razão e, consequentemente, da desrazão. Segundo Foucault, no texto 'A água e a loucura',

A loucura é o exterior líquido e jorrante da rochosa razão. É, talvez, a essa liquidez essencial da loucura nas nossas velhas paisagens imaginárias que devemos um certo número de temas importantes: a embriaguez, modelo breve e provisório da loucura; os vapores, loucuras ligeiras, difusas, enevoadas, em via de condensação em um corpo muito quente e uma alma abrasadora; a melancolia, água negra e calma, lago fúnebre, espelho em lágrimas; a demência furiosa do paroxismo sexual e de sua efusão7(205).

Apesar dos avanços conquistados pela Reforma Psiquiátrica, é fundamental a compreensão de que ela não é estática. Dito de outra maneira, é nodal que se compreenda que as leis e portarias são o início de um processo, e jamais seu fim. Ainda há muito que fazer no campo da saúde mental, considerando-se que o problema fundamental que parece se delinear extrapola esse campo específico, envolvendo questionamentos acerca do tipo de sociedade que se deseja, onde poderão ter lugar novas formas e saberes não estigmatizantes da loucura e não reforçadores da segregação social.

Foucault, no texto 'A loucura e a sociedade' (1970), aponta que, de modo geral, tem-se os 'domínios das atividades humanas' divididos em

quatro categorias: trabalho, ou produção econômica; sexualidade, família, quer dizer reprodução da sociedade; linguagem, fala; atividades lúdicas, como jogos e festas ${ }^{8(260)}$. 
Ao se considerar que a sociedade atual apresenta um estilo de organização no qual a capacidade de reconhecer o outro parece estar sob risco, pode-se pensar como essa articulação de território pode ser estabelecida no convívio entre a RT e a comunidade, a vizinhança que o recebe, em suas obrigações de cidadão - não somente em uma ideia equivocada de desinstitucionalização -, com sua inserção na lógica contemporânea.

Conforme apontado por Foucault, ainda se observa o predomínio de uma forma de relação excludente com a loucura, ainda não superada. Persistem, em nossa sociedade, a subjugação, o domínio e a destituição de saberes, considerando-se o louco como alguém a ser tutelado, na suposição de uma menoridade mental, civil e jurídica.

De qualquer forma, aqueles que são excluídos diferem de um domínio a outro, mas pode acontecer de a mesma pessoa ser excluída de todos os domínios: é o louco. Em todas as sociedades, ou quase todas, o louco é excluído de todas as coisas e, segundo o caso, ele se vê recebendo um status religioso, lúdico ou patológico ${ }^{\mathbf{8 ( 2 6 1 )} \text {. }}$

A ruptura dessa condição de vida parece ser possível tão somente quando a problematização da loucura ultrapassa a questão da diferença e adentra o âmbito da segregação social, a qual extrapola em muito o saber psiquiátrico e coloca a existência do louco no interior da realidade compartilhada por todos os fragilizados e segregados no tocante às possibilidades de troca social.

Lançado em 2015', no Brasil, o relatório da Comissão da Verdade Rubens Paiva versou sobre memórias manicomiais. No que concerne às conclusões dessa comissão, no relatório sobre ditadura e saúde mental, tem-se:

[...] sobejamente que essas instituições e esses profissionais foram historicamente usados no Brasil como instrumentos e agentes de poder e sujeição, seja por motivos políticos ou não. Na maioria dos casos, que não envolve militantes políticos, tratar-se-á de uma questão de resistência social, pela eficácia efetiva do direito social à saúde, que inclui necessariamente a saúde mental (São Paulo, Comissão da Verdade) ${ }^{\mathbf{9}(10)}$.

Esse relatório recomenda a:

[...] elaboração de um protocolo de atendimento, no campo da saúde mental, de integral respeito aos direitos humanos; reformulação dos moldes de tratamento de pessoas internadas em institutos de saúde mental, com o propósito de inibir as violações de direitos humanos, inclusive a tortura por meio de medicamentos (São Paulo, Comissão da Verdade)(12).

Nesse sentido, desde 2001, existe a Lei $\mathrm{n}^{\mathrm{o}} 10.216^{5}$, que redireciona o tratamento de pessoas acometidas por transtornos mentais. Essa Lei tenta garantir e propor a exclusividade do atendimento em ambiente extra-hospitalar, sendo a enfermaria de psiquiatria um local de atendimento de crises, que necessita de constante vigilância dos órgãos de Estado para que pessoas sob custódia não sejam mantidas por período maior que o necessário para superar a crise.

Retoma-se o último Censo Psicossocial (2014) $)^{\mathbf{1 0}}$, do governo do Estado de São Paulo, que revelou que ainda havia 4.439 pessoas na modalidade de moradores de hospitais psiquiátricos, resultando em uma diferença significativa em relação aos dados coletados no censo de 2008, no qual foram entrevistados 6.349 moradores. Em ambos os censos, foram encontrados números expressivos de pessoas que ainda residem em ambiente hospitalar. A partir da análise dos motivos pertinentes à redução de 1.910 pessoas entre os dados de um censo e outro, encontram-se: 1.170 óbitos, 739 altas para RT e o caso de um morador cujo destino não foi possível identificar. A informação de que o número de 
óbitos foi maior do que o de altas requer uma problematização acerca de quanto trabalho ainda precisa ser realizado no processo de desinstitucionalização.

Nessa perspectiva, a Comissão Estadual da Verdade (CEV) pode contribuir para a eficácia das preconizações na referida lei, responsabilizando o Estado e acompanhando a construção de RT para esses moradores, diante da impossibilidade de retorno à família de origem.

Em contrapartida, muitos atores envolvidos nas atrocidades praticadas contra esses moradores nos hospitais e na negação dos seus direitos à cidade não foram responsabilizados pelos seus atos. Quem responde pelas práticas manicomiais estabelecidas na história deste País? O próprio movimento de Luta Antimanicomial ainda questiona as práticas realizadas nesses hospitais, e, com frequência, pode-se utilizar o termo 'tortura' com relação às práticas cotidianas. Essa tortura se vincula tanto ao uso dos eletrochoques quanto à contenção medicamentosa - prática ainda existente -, assim como à proibição do acesso desses moradores à cidade. Desse modo, o relatório propõe que seja feita a

Investigação sobre as instituições e profissionais de saúde mental na violação de direitos humanos durante a ditadura militar, mais notadamente em relação à internação e à tortura de presos políticos nas instituições psiquiátricas9(12).

Nota-se que a reparação de danos se faz fundamental não somente em ações no âmbito da saúde. A loucura e seus estigmas ainda remontam ao pensamento estabelecido no passado. $\mathrm{O}$ retorno à cidade ainda encontra obstáculos nos episódios de 'exclusão social' vividos no cotidiano desses moradores.

A desospitalização, caminho inicial, muitas vezes é percebida como fim, como uma espécie de reparação de danos. Não restam dúvidas do quão irreparável é para todos os envolvidos nas atrocidades do manicômio. Como garantir que o papel social seja cumprido, assegurando efetivamente que essas pessoas sejam compreendidas como cidadãs? Nesse sentido, exemplos se seguem, tal como a discussão sobre a administração do dinheiro do morador, sem a curatela, que é algo que poderia ser pensado. A cidadania não pode existir mediante curatela. Um sujeito curatelado é menos cidadão que um sujeito que pode escolher, de fato, onde investir seus desejos.

Questões jurídicas são produzidas com frequência quando se obriga a curatelar um ex-morador de hospital psiquiátrico, para que ele possa ter acesso a seus benefícios. Considerar que o sujeito-cidadão não seja 'curatelado', mas 'ajudado' pelos profissionais que o acompanham na gestão do próprio dinheiro, é imprescindível. Assim, urge a construção de documentos norteadores que garantam que os profissionais de saúde possam compreender a cidadania desse usuário e que orientem sobre como este pode administrar o seu dinheiro sem a necessidade de que o outro responda por sua curatela.

A reparação de danos se dá na garantia da cidade em sua amplitude da convivência assegurada a todos os cidadãos, em sintonia com seu desejo de ir e vir, nem sempre encontrada em razão dos inúmeros critérios de exclusão presentes no cotidiano da cidade.

Outra pergunta que se faz: onde pode morar alguém que antes vivia confinado em um hospital psiquiátrico? Não há dúvida de que, a depender das características do bairro - população, poder aquisitivo, receptividade, entre outras mais -, esses moradores são bem acolhidos. Mas o lugar de moradia seria estabelecido por esses critérios?

Segundo Butler, é a impossibilidade de que se reconheça a vida desses alguns que faz com que os coloquemos à parte, afastados dos que podem viver em sociedade. Assim, a apreensão da vulnerabilidade de um corpo/ser precário conduz a uma "potencialização da violência, a uma percepção 
da vulnerabilidade física de certo grupo de pessoas que incita o desejo de destruí-las"1(15). No cotidiano da cidade, os loucos são vítimas constantes dessas violências. A autora propõe a necessidade de

[...] ampliar as reivindicações sociais e políticas sobre os direitos à proteção e o exercício do direito à sobrevivência e à prosperidade, a vulnerabilidade, a dor, a interdependência, a exposição, a subsistência corporal, o desejo, o trabalho e as reivindicações sobre a linguagem e o pertencimento social'(15).

Apreender uma vida depende de que essa vida seja produzida de acordo com algumas regras estabelecidas. Segundo a autora, tem-se um problema ético quando essa vida precisa ser reconhecida e, por sua vez, protegida contra a violação. Para que o sujeito seja reconhecido, ele precisa estar enquadrado nos parâmetros das normas sociais vigentes.

Os esquemas normativos são interrompidos um pelo outro, emergem e desaparecem dependendo de operações mais amplas de poder, e com muita frequência se deparam com versões espectrais daquilo que alegam conhecer. Assim, há 'sujeitos' que não são exatamente reconhecíveis como sujeitos e há 'vidas' que dificilmente - ou, melhor dizendo, nunca - são reconhecidas como vidas ${ }^{\mathbf{1 ( 1 7 )}}$.

A reparação de danos segue na aquisição e na garantia do auxílio à reabilitação, que não poderia ser provisório, e, sim, vitalício, na criação de quantas RT fossem necessárias para que não haja moradores em hospitais psiquiátricos, e na responsabilização real do Estado com relação a qualquer forma de internação que não seja necessária.

Nesse sentido, a indenização de todo cidadão, vítima de violência por ser louco, é ponto importante no enfrentamento dos estigmas presentes na compreensão da loucura. A responsabilidade da sociedade para com as violências sutis do cotidiano é exemplificada pelos profissionais de saúde que se negam a atender um usuário do serviço de saúde mental sozinho na unidade de saúde, ou que renegam a sua presença ao conversarem somente com o seu acompanhante, incapacitando-o por ser louco ou por ser simplesmente diferente.

Quando se retira o hospital como moradia, precisa-se reconhecer a precariedade da vida dessas pessoas, que não difere da precariedade que une todos os humanos e, também, os não humanos. Nesse sentido, e a partir desse reconhecimento, a garantia de suprir as necessidades de todos se mostra fundamental. Aos que, individualmente, não conseguiram, é papel do Estado suprir habitação, alimentação, saúde, trabalho e justiça. Com relação à parcela que a sociedade isolou nos manicômios por acreditar que não tivesse condições de viver entre os demais, é preciso reconhecer de forma igualitária a precariedade de sua realidade e a sua necessidade de cidadania.

\begin{abstract}
A precariedade implica viver socialmente, isto é, o fato de que a vida de alguém está sempre, de alguma forma, nas mãos do outro. Isso implica estarmos expostos não somente àqueles que conhecemos, isto é, dependemos das pessoas que conhecemos, das que conhecemos superficialmente e das que desconhecemos totalmente1(31).
\end{abstract}

Os loucos na cidade denunciam essa condição, negada no cotidiano. São eles que, sem se preocupar, colocam-se na interdependência com a cidade, perguntando, questionando e solicitando atenção. A própria noção de alteridade se impõe radicalmente a partir do que os loucos na cidade mostram. Vale lembrar que no cotidiano das vidas comuns, centrado na individualidade e no desejo pelo imediato, a experiência de alteridade está posta em cheque e colocada em tensão.

Aqui, a reparação de danos articula-se com a exclusão social, ampla e fora dos antigos muros que protegiam a sociedade 
do louco, mas que também o protegiam das cotidianas e sutis violências a que muitos outros, mesmo sem serem loucos, estão expostos. O que podemos enfatizar é que, na exclusão social, essas pessoas se somam também a outras parcelas da sociedade que têm no cotidiano de suas vidas seus direitos obstaculizados e, tantas vezes, negados.

Destarte, esses problemas convergem na compreensão de uma sociedade excludente para com muitos de seus habitantes, todos sem voz, seja pelos seus delírios ou pela negação do discurso: loucos, população em situação de rua, refugiados, negros, gays, lésbicas, travestis, transexuais, usuários de álcool e outras drogas e tantos outros.

Em suma, os moradores das RT são ex-moradores de hospitais psiquiátricos e, por vezes, possuem outras marcas estigmatizantes, como a cor e a pobreza, e, por vezes, denunciam os absurdos obscurecidos pela rotina, violências sutis presentes nas buzinas quando, distraídos, andam fora da calçada, numa cidade que não para e cujos códigos de sobrevivência são mais rígidos do que se imagina. Assustam, gritam, choram sem pudor, soltam gargalhadas sentados em um banco de praça, andam pelas ruas, cumprimentam os vizinhos, falam sozinhos em voz alta, desconhecem o código de civilidade que demarca a vida urbana, do anonimato, da cordialidade discreta, dos limites relacionados ao espaço do outro. São pessoas, como todos os outros que frequentam os mesmos espaços, porém, carregam no corpo a precariedade, precariedade que o restante da população não reconhece como fundamental e que requer um esforço de negociação mínima e respeito para com sua existência singular.

A reparação de danos exige reconhecimento, para que possa ser operada na sociedade por meio do enfrentamento da condição de vida das parcelas socialmente vulneráveis e da sua concreta inserção na sociedade como cidadãos de direito, reconhecidos como sujeitos. Esbarra-se, aqui, num problema mais amplo, denominado cultura, cuja historicidade demarca uma constante dificuldade em lidar com as diferenças sem recorrer a classificação, hierarquização e segregação. Trata-se de uma cultura narcísica, pautada pelo encontro e pela reverência ao que espelha ela própria. 


\section{Referências}

1. Buttler J. Quadros de guerra: quando a vida é passível de luto? São Paulo: Boitempo; 2015.

2. Arbex D. Holocausto Brasileiro. São Paulo: Geração Editorial; 2013.

3. Merleau PM. Fenomenologia da percepção. São Paulo: Martins Fontes; 1999.

4. Brasil. Ministério da Saúde. Portaria/GM no 106, de 11 de fevereiro de 2000. Institui os Serviços Residenciais Terapêuticos no âmbito do SUS. Diário Oficial da União. 11 Fev 2000.

5. Brasil. Lei $\mathrm{n}^{0} 10.216$, de 6 de abril de 2001. Dispõe sobre a proteção e os direitos das pessoas portadoras de transtornos mentais e redireciona o modelo assistencial em saúde mental. Diário Oficial da União. 6 Abr 2001.

6. Ortega F. Amizade e estética da existência em Foucault. Rio de Janeiro: Graal; 1999.

7. Foucault M. A água e a loucura. In: Problematização do sujeito: psicologia, psiquiatria e psicanálise. 2 ed.

Rio de janeiro: Forense Universitária; 2002.

8. Foucault M. A loucura e a sociedade. In: Problematização do sujeito: psicologia, psiquiatria e psicanálise. 2. ed. Rio de janeiro: Forense Universitária; 2002.

9. São Paulo (Estado). Comissão da Verdade. Ditadura e saúde mental (Relatório) [internet]. São Paulo: Comissão da Verdade; 2015. Tomo I; Parte II [acesso em 2017 jan 2]. Disponível em: http://comissaodaverdade.al.sp.gov.br/relatorio/tomo-i/ downloads/I_Tomo_Parte_2_Completa.pdf.

10. Cayres AZF, Ribeiro MC, Elias R, et al, organizadores. Caminhos para a desinstitucionalização no Estado de São Paulo: censo psicossocial 2014. São Paulo: FUNDAP; 2015.

Recebido em 21/10/2017

Aprovado em 02/03/2018

Conflito de interesses: inexistente

Suporte financeiro: não houve 